\title{
Review
}

\section{Follow-up care for persons with spinal cord injury living in the community: a systematic review of interventions and their evaluation}

\author{
JHA Bloemen-Vrencken*,1,2, LP de Witte ${ }^{2,3}$ and MWM Post ${ }^{3,4}$ \\ ${ }^{1}$ Rehabilitation Centre Hoensbroeck, Hoensbroek, The Netherlands; ${ }^{2}$ Institute for Rehabilitation Research, iRv, \\ Hoensbroek, The Netherlands; ${ }^{3}$ University of Maastricht, The Netherlands; ${ }^{4}$ Rehabilitation Centre De Hoogstraat, \\ Utrecht, The Netherlands
}

Study design: Systematic review.
Objectives: (1) To describe and compare follow-up care programmes, performed by
rehabilitation centres, for persons with spinal cord injury (SCI) and (2) to describe the effects
of these programmes regarding the occurrence of secondary impairments, well-being, the quality
and costs of care.
Methods: A systematic literature search was conducted in MEDLINE (1972-2003) and
CINAHL (1982-2003). Publications were selected about medical and/or nursing follow-up care
to SCI patients living in the community performed by or with rehabilitation facilities for SCI
patients. The aim of the follow-up care should be a decrease of secondary impairments, an
improvement of well-being, an improvement of the quality and/or a decrease of the costs of
care.
Results: The search resulted in 24 papers. The descriptions of the programmes in these papers
were sometimes rather scattered, vague or brief. The most important methods were telemedicine
(six programmes; of which five were performed in the same rehabilitation centre), outpatient
consulting hours (six programmes), home visits (three programmes, and case management (one
programme). Eight other programmes combined several methods (ie outpatient consulting
hours, home visits, peer teaching and support, outings, ongoing support, therapy from several
care disciplines, SCI education, providing SCI expertise and support to community health-care
providers, coordination of care with community nursing agencies). In all, 16 programmes have
been evaluated to some degree. In general the quality of the studies was low. Most evaluations
were pre-experimental in design. Only three were quasi-experimental, and two programmes were
experimental in design. Although several studies claimed positive effects, it was not possible to
draw conclusions on the effect of follow-up care on the occurrence of secondary impairments,
well-being, the quality and costs of care. Conclusion: There is a need for the development, the publication and the well-designed evaluation of follow-up care programmes for persons with SCI.

Spinal Cord (2005) 43, 462-475. doi:10.1038/sj.sc.3101750; published online 19 April 2005

Keywords: follow-up care; long-term care; spinal cord injuries

\section{Introduction}

Since persons with spinal cord injury (SCI) are confronted with all kinds of short- and long-term problems in functioning after discharge from initial rehabilitation, the need for continuing care for persons with SCI living in the community has been emphasised in several reports. ${ }^{1-8}$

\footnotetext{
*Correspondence: JHA Bloemen-Vrencken, Institute for Rehabilitation Research (iRv), PO Box 192, 6430 AD Hoensbroek, The Netherlands
}

Until recently follow-up care provided by the Dutch rehabilitation centres has consisted of periodical outpatient visits to a physiatrist. During these visits a comprehensive assessment of total functioning is performed and, if necessary, interventions or other support is given. After discharge from clinical rehabilitation, daily medical and nursing care for persons with SCI is usually given by primary care professionals. As a result of the low prevalence of persons with SCI, primary health-care professionals only sporadically have persons with SCI in their practice. Consequently, they do not 
often have much opportunity to gain sufficient knowledge and experience about the specific care these patients need. As a result of this and the high prevalence of health problems, rehabilitation teams want to extend their role in follow-up care to persons with SCI living in the community.

In order to be able to learn from other initiatives regarding follow-up care, this systematic review was initiated. At present there is no systematic overview of the content follow-up care programmes and the effects on the prevalence of health problems.

The purpose of this paper is to provide an overview of published follow-up care programmes provided by rehabilitation centres to persons with SCI after their in-patient and outpatient rehabilitation. This study is focused on medical and nursing follow-up care, since most problems SCI patients experience are within the scope of the medical and nursing profession. The second objective is to describe the effects of these published follow-up care programmes on the occurrence of secondary impairments, well-being, the quality and costs of care.

\section{Methods}

\section{Search strategy}

Publications were selected from the MEDLINE (19722003) and CINAHL (1982-2003) databases. In all search strategies we combined several terms for spinal cord injuries (ie tetraplegia, paraplegia, spinal cord injuries) with a broad range of keywords related to follow-up care (ie follow-up care, long-term care, aftercare, continuity-of-patient care, patient discharge, outpatient care, ambulatory-care-facilities, primaryhealth care, home care, home rehabilitation, community care, disease management, shared care). The search strategy is described in Figure 1. The definition of a keyword given in the thesaurus list of the databases was used to determine whether a keyword was appropriate to use in the search strategy. Only publications written in Dutch, English or German were taken into consideration.

\section{Selection procedure}

A publication was selected if it described medical and/or nursing follow-up care to persons with SCI living in the community after their in-patient- and outpatient rehabilitation. The aim of the follow-up care should be a decrease of secondary impairments, an improvement of well-being, an improvement of the quality and/or a decrease of the costs of care. Furthermore, it should describe follow-up care performed by or in cooperation with rehabilitation facilities for SCI patients.

The first phase of the selection was performed by three investigators ( $\mathrm{LW}, \mathrm{MP}$ and $\mathrm{JB}$ ) by reading the titles and, if available, the abstracts of all the initially identified publications. All publications selected by at least two of the three investigators were obtained and studied by the first investigator (JB) in order to

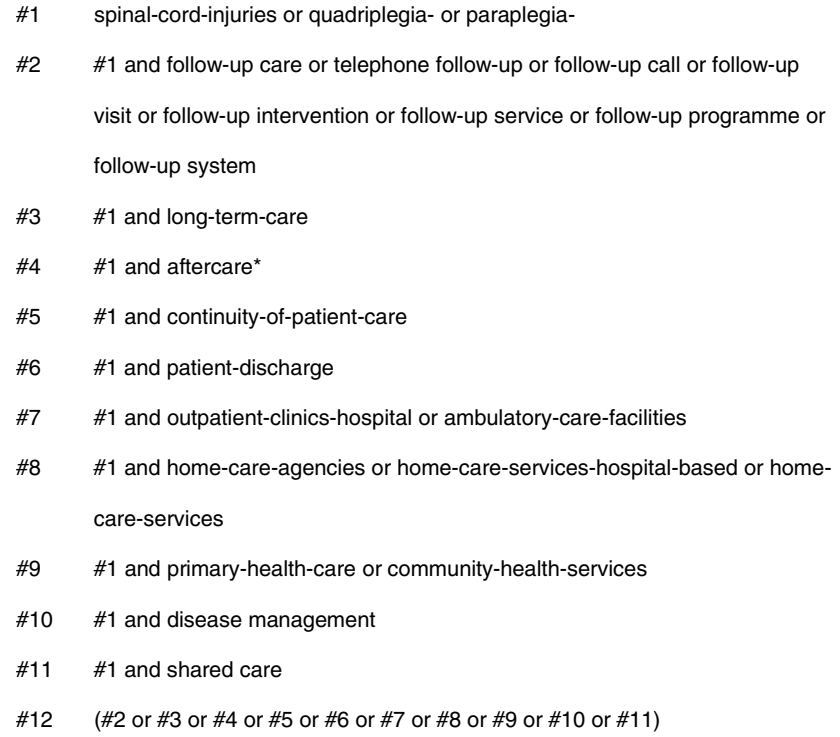

Figure 1 Search strategy

determine whether the inclusion criteria mentioned indeed were applicable. In case of doubt on selection of a publication, the other investigators were consulted.

\section{Assessment of selected follow-up care interventions}

The follow-up care programmes were systematically described with respect to the aims, target population, method, responsible care disciplines, and content of the follow-up care. If there was a control/comparison group, the content of the treatment the persons in this group received was also described.

Follow-up care programmes that had been evaluated were described with respect to design, number of patients, outcome measures, and results. The studies were categorised as experimental, quasi-experimental or pre-experimental, according to the classification as described by Polit and Hungler. ${ }^{9}$ In this classification an experiment is defined as a study in which the investigator controls (manipulates) the independent variable and randomly assigns subjects to different conditions. Quasi-experiments involve manipulation but lack a comparison group or randomisation. In quasi-experiments efforts are made to introduce controls to compensate in part for the absence of one or both of these important characteristics. Pre-experiments do not include controls to compensate for the absence of either randomisation or a control group.

\section{Results}

Results of the search strategy

The search for publications resulted in almost 800 titles of which 99 were selected by at least two of the three researchers as being possibly relevant. The types of these 99 publications varied. Only a minority had a scientific format, including an abstract, introduction, methods, results, discussion, and conclusion section. Also some 
letters to an editor, a job description, and a research abstract were included. Sometimes it was hard to decide whether or not to include a publication, because, for example, the information about the follow-up care was too brief. Finally, 24 of the 99 initially selected publications were included in this review.

The reasons for not including the remaining 75 publications varied. A total of 17 publications focused on the care during rehabilitation and discharge-preparation, 10 publications focused on the importance of follow-up care, but did not describe a programme, eight publications described or evaluated care provided by primary care professionals only, two described inpatient care programmes for patients readmitted due to pressure sores, two publications reported health problems after discharge, and the remaining 35 publications were excluded for all kinds of reasons (eg publications focusing on the importance of good education materials, a well-organised continuum of care, health problems after discharge, case descriptions not dealing with follow-up care provided by the rehabilitation centre).

\section{Intervention characteristics}

Table 1 displays the aims, methods used, care disciplines responsible, and content of the follow-up care programmes identified.

Principle methods of the follow-up care programmes Five methods of follow-up care could be identified from the descriptions in the selected articles:

(a) Telemedicine, the use of telecommunications technology that either delivers or supports the delivery of health services and education via long distance. ${ }^{10-15}$ Five of these six projects were performed by the same rehabilitation centre, that is, Shepherd Centre, Atlanta, USA. Since both the content and to some extent the aims were different for each follow-up care programme, all these projects were included in this review.

(b) Outpatient consulting hours providing physicals, reviews of daily functioning and support in case of health problems. ${ }^{16-21}$

(c) Home visits. ${ }^{22-24}$

(d) Case management, involving the coordination of care within, between, and beyond the acute and rehabilitation programmes, extending care and coordination to the community and managing the reemerging needs of the population over time. ${ }^{25}$

(e) Miscellaneous types of follow-up care consisting of several of the following methods: outpatient consulting hours, home visits, peer teaching and support, outings, ongoing support, therapy from several care disciplines, SCI education, providing SCI expertise and support to community health-care providers, coordination of care with community nursing agencies. ${ }^{26-33}$
Aims of follow-up care programmes Prevention and/or treatment of secondary impairments was the most frequently mentioned aim of the follow-up care programmes. Two-thirds of the follow-up care programmes included this in their aims. ${ }^{10-14,16-18,22,24-30}$ Six followup care programmes solely aimed at the prevention and/or treatment of a specified secondary impairment: pressure sores, ${ }^{10-13,17}$ and urinary tract infections. ${ }^{16}$ Beside this, several of these programmes also had a broader aim like the promotion of well-being and community reintegration. ${ }^{12,18,22,25,26,28-30}$

In several publications ${ }^{13,18-22,28,29,32}$ the aim of the follow-up care was not stated explicitly, although in most cases an aim could be derived from the text.

Target population of follow-up care programmes The target population in all follow-up care programmes was persons with SCI recently discharged from rehabilitation and living in the community. Some care programmes also involved in-patients. ${ }^{17,25,31,33}$ The follow-up care programme described by Beck $^{26}$ was designed for persons with tetraplegia and their longterm health-care providers. Several care programmes regarded persons with SCI and their partners or families. ${ }^{19,21-25,27,32,33}$

Responsible care disciplines Almost half of the follow-up care programmes were performed by nurses. ${ }^{10-14,16,22,24-26,33}$ The remaining programmes were performed by several care disciplines. In the follow-up programme described by Pollack, ${ }^{31}$ the participants had coresponsibility in the performance. The follow-up care programmes described by Dover, ${ }^{17}$ Lapierre, ${ }^{20}$ and Dinsdale ${ }^{28}$ were performed in collaboration with primary health-care providers. Several followup care programmes ${ }^{15,21,23-26,28,30}$ paid attention to the coordination of care with community care agencies/ providers, for example, by providing SCI expertise, support and communication of information regarding assessments and treatment plans.

Content of the follow-up care programmes The degree in which the content of the follow-up care programmes were described was very diverse. The content of patientcaregiver contacts or education were for instance sometimes elaborated, and sometimes not. Sometimes it was hard to distinguish the difference between the follow-up programme and usual care. Sometimes the description of the content of follow-up care described rather scattered, vague, and brief.

Except for the follow-up care described by Steinberg, ${ }^{32}$ the programmes did not include home therapy or home health aid, for simple nursing procedures such as baths, enemas, etc. Most follow-up care programmes had a supportive, consultative and educative character. 
Table 1 Follow-up care characteristics

\begin{tabular}{ll}
\hline Author & Aim \\
\hline Mathewson $^{10}$ & $\begin{array}{l}\text { Long-distance delivery of medical } \\
\text { education and services to patients } \\
\text { with pressure ulcers }\end{array}$ \\
Mathewson $^{11}$ & To prevent pressure ulcers
\end{tabular}

Principle method

Care disciplines responsible

Content

Telemedicine

An ET nurse (abbreviation not explained)

Distant care using a videophone (audio and still images)

Mathewson $^{11}$ To prevent pressure ulcers

Telemedicine $\begin{array}{ll}\text { Phillips }^{12} & \begin{array}{l}\text { To prevent pressure ulcers and to } \\ \text { assist in community reintegration }\end{array} \\ \text { Phillips }^{13} & \text { Not described directly }\end{array}$

Indirectly: to prevent pressure sores and hospitalisations due to pressure sores, to promote the most effective care of sores that develop

Phillips $^{14} \quad$ To reduce the incidence of secondary conditions

Telemedicine

\section{Telemedicine}

A wound, ostomy and continence nurse

A nurse

Video group and telephone group: a nurse

standard care group: not described

Video group and telephone group: a nurse

standard care group: not described
Structure: weekly contact for 5 weeks and then every other week

Two interventions: (1) Telerehabilitation: distant care using a videophone (audio and still images);

Structure: weekly contact for 5 weeks and then every other week

(2) Contingency management: a procedure whereby the patient receives monetary compensation upon keeping his skin free from pressure sores

Weekly videophone contacts (audio and still images)

Two interventions:

(1) Video intervention: videophone (audio and still images) and telephone counselling sessions providing support related to pressure sores, problems related to wheelchairs, mattresses, and mobility;

Structure: weekly videophone contacts for the first 6-8 weeks following discharge, followed by weekly telephone contacts for 4-6 weeks

(2) Telephone intervention: telephone counselling providing skin checkups and support related to diet, bowel problems or other problems;

Structure: weekly contacts for approximately 10 weeks after discharge

The comparison group received standard care: information and counselling for patients who call the help line of the rehab centre

Two interventions:

$(1,2)$ Video and telephone intervention: individual educational sessions regarding skin care, nutrition, bowel and bladder routines, psychosocial issues, and equipment needs

Referrals to a mental health counsellor or other professionals if necessary

The video group also saw real-time images of the nurse (audio and still images)

Structure: weekly contacts for 5 weeks, then once every 2 weeks for 1 month

The control group received standard care: requires patients to call the help line of the rehab centre

A hub-and-spokes model is used to link a major spinal cord injury/disease (SCI/D) centre to nonspecialty outpatient clinics 
Table 1 Continued

\begin{tabular}{|c|c|c|c|c|}
\hline Author & Aim & Principle method & Care disciplines responsible & Content \\
\hline & & & & $\begin{array}{l}\text { Veterans present themselves to the satellite outpatient } \\
\text { clinic nearest their homes. After that a } \\
\text { teleconsultation visit is arranged with the appropriate } \\
\text { interdisciplinary team member at the SCI/D centre } \\
\text { Each outpatient clinic has a } 2 \text {-way interactive video } \\
\text { module and a personal telemedicine module } \\
\text { containing a speakerphone, blood pressure and pulse } \\
\text { meter, a telephonic stethoscope, and a handheld } \\
\text { digital camera }\end{array}$ \\
\hline Barber $^{16}$ & $\begin{array}{l}\text { To reduce urinary tract infections in } \\
\text { patients identified as at risk }\end{array}$ & $\begin{array}{l}\text { Outpatient consulting } \\
\text { hours }\end{array}$ & A nurse & $\begin{array}{l}\text { Review of patient's urologic history, medical } \\
\text { interventions if necessary, counselling (one session; } \\
15-30 \text { min) by the nurse with respect to proper clean } \\
\text { intermittent catheterisation, hygiene, and other } \\
\text { aspects of bladder management. If the patient had } \\
\text { multiple urinary tract infections during the following } \\
6 \text { months, continuous low-dose antibiotics were } \\
\text { initiated. Counselling was repeated during } \\
\text { subsequent clinical visits. All activities are described } \\
\text { in a care path }\end{array}$ \\
\hline Dover $^{16}$ & $\begin{array}{l}\text { To assess, advise and educate with } \\
\text { regard to pressure sore prevention }\end{array}$ & $\begin{array}{l}\text { Outpatient consulting } \\
\text { hours }\end{array}$ & $\begin{array}{l}\text { A nurse and an occupational } \\
\text { therapy technician from the }\end{array}$ & $\begin{array}{l}\text { Visits to a clinic (both in-patient and outpatient), in } \\
\text { which patients are taught to take responsibility for }\end{array}$ \\
\hline
\end{tabular}

regard to pressure sore prevention hours therapy technician from the To assess each patient's susceptibility rehabilitation centre, and a to pressure sores

To link with the community liaison

nurse

Dunn $^{18} \quad$ Not described directly

Indirectly: wellness, health

Outpatient consulting

rehabilitation centre, and
community liaison nurse

promotion, and illness prevention.

To prevent and reduce the number

Ferguson $^{19}$ Not described

Outpatient consulting Several care disciplines

hours

Outpatient consulting

Lapierre $^{20} \quad$ Not described directly

Indirectly: to improve continuity of care between primary and tertiary health-care services
hoursOutpatient

consulting hours in a
A primary care neurospinal nurse practitioner in collaboration with several care disciplines

which patients are taught to take responsibility for

their own well-being, an education programme, and

home visits by a community liaison nurse after

discharge

The comparison group received their in-patient

rehabilitation in another rehabilitation centre and

were attending the pressure clinic as outpatients for the first time

A comprehensive, interdisciplinary primary healthcare follow-up (not being described in more detail) The comparison group did not receive health-care follow-up

Annual physicals and an individualised plan of care A peer support group that meets in the hospital, and a community outreach and reintegration group that meets in the community

Managing, directing and providing comprehensive care in a collaborative multidisciplinary team Activities are also referrals to other disciplines, consultation to other specialties, and collaboration with primary providers

When issues are clearly primary or rehabilitative in nature, patients are assessed in collaboration with the physiatrist 
Beer $^{22}$

Not described directly

Indirectly:

Home visits

A home visiting nurse

Achieve the primary aim of a

preventative nursing role

Reduce the number of re-admissions to the spinal unit

Help maintain social and domestic

stability, and achieving independence for patients

Fine $^{23} \quad$ The assessment of architectural barriers in the place of residence and

the need for equipment, and provision of direct patient care

Jones $^{24}$

Prevention

Facilitating difficult discharges

Home visits

A nurse

Finding lost cases

Cioschi $^{25}$ Ensuring access of patients into an SCI system of care, so that expert, coordinated care can be delivered,

complications can be minimised, and initial and long-term health-care costs can be reduced

Beck $^{26}$

To optimise individual and societal Mixed methods outcomes. To decrease the frequency of readmissions, and to enhance

continuity of care

Brown $^{27} \quad$ Medical follow-up, prevention and Mixed methods

treatment of complications, ongoing

support and education of the patient

and his family

Dinsdale $^{28} \quad$ Not described directly

Indirectly: Re-integration and

maintenance of physical well being
Mixed methods

Several care disciplines specialists
Outpatient consulting hours, referrals to in-hospital services when appropriate, telephone contacts in case of emergent problems, and SCI teaching and

counselling to patients, partners, and caregivers Home visits to the family prior to discharge for support and re-teaching.

Home visits after discharge to help with the reintroduction to home life, giving emotional and practical support, and identifying physical problem and directing patients to the appropriate specialist

A registered nurse, a registered physical therapist, and a vocational rehabilitation counsellor

Predischarge home visits to assess architectura barriers and the need for equipment, and to provide education and support to family members

Home visits at several intervals after discharge to provide direct care and education

Following each home visit, a patient status report is distributed to local community health resources which provide ongoing care

Home visits to provide 'preventive' advice and instruction to patients, relatives, and district nurses. Sometimes these visits are combined with the visit of the family doctor, welfare officers, and/or district nurses A broad scale of interventions is described in the article, including medical/functional problem identification and early intervention, the coordination of care and resources, gate keeping functions that access appropriate health-care, identifying functional outcomes as they relate to the need for ongoing therapeutic interventions, and facilitating community reintegration

Rehabilitation clinical nurse

Education, assessment and intervention by means of a 1-day workshop, educational pamphlets, home visits and problem driven ongoing support during a 12-month period

Several care disciplines

Team reviews as often as is necessary for the first year after discharge, and then at yearly intervals

Visits to home, visits to community facilities, and visits to work place

Readmission in case of illnesses, injuries or other problems

Community based follow-up:

Assessments by the public health nurse during the first week of discharge, at 6-month intervals for the first 2 years, and annually thereafter. A summary of the findings is communicated to the rehabilitation centre and the family physician 
Table 1 Continued

\begin{tabular}{|c|c|c|c|c|}
\hline Author & Aim & Principle method & Care disciplines responsible & Content \\
\hline Duci $^{29}$ & Not described directly & Mixed methods & Several care disciplines & $\begin{array}{l}\text { A home visit by the rehabilitation liaison nurse and } \\
\text { the public health nurse in the first week postdischarge } \\
\text { Procedures to organise medical care when necessary } \\
\text { (by the rehabilitation team and/or primary health- } \\
\text { care providers) } \\
\text { A review in the spinal cord clinic at six weeks } \\
\text { postdischarge for assessment by the physiatrist and } \\
\text { other rehabilitation members } \\
\text { Post discharge urological management by an } \\
\text { urologist } \\
\text { Providing expertise and support to the community } \\
\text { health resources by the physiatrist and rehabilitation } \\
\text { liaison nurse } \\
\text { The comparison group received hospital-based } \\
\text { follow-up: care provided by the physiatrist in } \\
\text { cooperation with the family physician; } \\
\text { Reviews by the physiatrist at } 6 \text { weeks and every } 6-12 \\
\text { months thereafter } \\
\text { Procedures to organise medical care when necessary } \\
\text { (by the rehabilitation team) } \\
\text { A home visit } 2 \text { or } 3 \text { weeks after discharge }\end{array}$ \\
\hline
\end{tabular}

Indirectly: to reinforce the teaching,

training, and support given to the

patient and his family to help them

make the transition to an

independent, productive living

situation

Lathbury $^{30} \quad$ To reinforce skills learned during hospitalisation, prevent secondary

medical complications, and help with financial, social or accessibility problems
Mixed methods

A community re-entry specialist, a vocational rehabilitation counsellor,

and a rehabilitation technician

Several care disciplines with coresponsibility of the participants
A home visit 2 or 3 weeks after discharge

Outings for groups or individual patients (ie camping trip, sports game)

Assessments of retraining capabilities and

employment motivation

Peer teaching and counselling

Support to organise attendant care and regaining control of the patient's situation

An assisted learning programme including educational videotapes which reteach skills and introduce new skills

Promotion of networking with and among SCI

persons in the community

Consultation and education of community nursing agencies

Extended care consists of two elements

visits in which attention is paid to

community involvement, recreation activities,

transportation, mobility skills, accessibility issues, return-to-work or school opportunities, explaining procedures to caregivers or home health nurses, and providing on-site reviews of the home

(2) An ongoing peer support programme

(1) Informational sessions once a month, with topics being suggested by the participants and the

committe 
knowledge base. To improve

problem-solving skills and self-

esteem. To develop one-on-one

support, counselling and guidance.

To facilitate community resource

networking. To enhance socialisation

$\begin{array}{ll}\text { Steinberg }^{32} & \text { Not described directly } \\ & \text { Indirectly: to ease the transition }\end{array}$

Indirectly: to ease the
from hospital to home

Warner $^{33}$ To evaluate the effectiveness of the discharge plan and patient teaching and to provide interventions in case of problems

(2) Peer support groups once a month

(3) A peer counsellor training and matching

programme

Several care disciplines

Mixed methods

Mixed methods

A nurse
Nursing, social service, physical and occupational therapy and home health aides: by means of home visits, home health aid, and home therapy,

instruction and education

Hospital-readmission when necessary

Reviews in the hospital at least once a year

(1) A predischarge home visit as soon after admission as possible to assess family strengths and weaknesses, the home, data about the community, and local health services

(2) A postdischarge visit within 8 weeks after discharge to reassess the home programme and evaluate teaching and patient compliance. It

consisted of a visit to patients' homes, their place of employment or school, and communication with the community health nurse. Teaching and counselling were carried out as necessary

(3) Ongoing communication with patients, families and team members by phone calls and seeing patients in the clinics 


\section{Evaluation characteristics}

Table 2 describes the design, number of patients, outcome measures, and outcomes of the studies that evaluated follow-up care programmes. In all, 16 out of the 24 follow-up care programmes had been evaluated to some degree.

Designs of evaluation In all, 11 evaluations were preexperimental, ${ }^{10,12,16,20,22-25,30-32}$ three studies were quasi-experimental, ${ }^{13,17,18}$ and two studies were experimental in design. ${ }^{14,28}$

Number of patients The number of patients included in the evaluation studies varied from 1 to 519 persons with SCI. Four evaluations of follow-up care did not mention the number of patients. ${ }^{20,22,24,31}$

Outcome measures Several publications did not define the outcome measures in a methodology section. ${ }^{10,12,16,17,20,24,26,32}$ The outcome measures of these publications, mentioned in Table 2, have been derived from the descriptions of the results. Almost all studies used post-test-only measurements. In a few studies, partly pretest-post-test measurements were performed. ${ }^{16,26,32}$ Five types of outcome measures could be identified from the descriptions in the selected articles:

(a) the incidence and/or improvement of secondary impairment(s); ${ }^{10,13,16-18}$

(b) health-care utilisation: for example, the number and duration of hospital readmissions, and the number of follow-up care contacts; ${ }^{10,12-14,17,22-24,26,28,32,33}$

(c) satisfaction with the care, ${ }^{2,20,26}$

(d) costs of the care, ${ }^{10,23}$

(e) other outcome measures: for example, self-reported health, independence, knowledge, and the level of functioning. ${ }^{2-14,18,24,26,28,31-33}$

Results of the evaluations Most pre-experimental studies claimed positive effects of the follow-up care, although it was sometimes hard to derive this from the results presented. As a result of the pre-experimental design, the results of the evaluations are not included in the evaluation here.

The following effects were found in the quasiexperiments and experiments:

(a) Incidence and/or improvement of secondary impairments: improvements were found in two ${ }^{17,18}$ of the three studies investigating the effects on this variable. In one of these studies ${ }^{17}$ there was no test for significance. Phillips ${ }^{13}$ found a higher incidence of pressure sores in the intervention group, but stated that the follow-up care appeared to improve ulcer tracking and management. (b) Health-care utilisation: three $14,17,28$ out of four studies investigating the effects on this variable found a decline of health-care utilisation, although no information was provided about the statistical testing of the findings. The remaining study ${ }^{13}$ reported more hospitalisations in the intervention groups compared with the comparison group, although this difference was not significant.

(c) Other outcomes: Phillips ${ }^{13}$ found a higher postinjury employment rate in the intervention group, although this difference was not significant. Dunn ${ }^{18}$ reported significantly better subjective health, independence and less depression in the experimental group. In another study Phillips ${ }^{14}$ found, at 1-year postdischarge, significantly higher scores of the quality of well-being in both the intervention groups. On the other hand, at one-year post-discharge, the video group had more depressive symptoms than the telephone or standard care group. Dinsdale ${ }^{28}$ found no differences with respect to ADL, integration (school and work), and needs detected at follow-up. However, more emotional, housing, vocational and health agency support was used in the intervention group.

\section{Discussion}

The literature search provided only a small number of descriptions of follow-up care programmes. The description of the content of these programmes sometimes was rather scattered, vague and brief. Five methods of follow-up care were identified: telemedicine, outpatient consulting hours, home visits, case management, and mixed types of follow-up care.

In all, 16 out of the 24 follow-up care programmes have been evaluated to some degree. Health-care utilisation was the most frequently studied outcome measure, followed by the incidence and/or improvement of secondary impairment(s). Only a small number of studies paid attention to the effects of follow-up care on the satisfaction with the care, the cost of care, health, and independence. In general, the quality of the evaluation studies was low. Most evaluations were preexperimental in design. Only three were quasi-experimental, and two were experimental in design. Although several studies found positive effects, it was not possible to draw general conclusions on the effect of follow-up care on the occurrence of secondary impairments, well-being, the quality and costs of care. It can be concluded that the effectiveness of follow-up care programmes for persons with SCI remains far from proven.

The results of this review may, however, be limited for several reasons. First, it may be questioned whether all possible relevant articles were detected. However, we searched the MEDLINE and CINAHL databases, made use of a combination of MeSH (indexing terms) and text words that covered a wide range of the research field, tried other search strategies too, and studied all 
Table 2 Evaluation characteristics

\begin{tabular}{|c|c|c|c|c|}
\hline Author & Design & $\mathrm{N}$ & Outcome measures* & Outcomes $^{\mathrm{a}}$ \\
\hline Mathewson $^{10}$ & Pre-experiment & 1 & 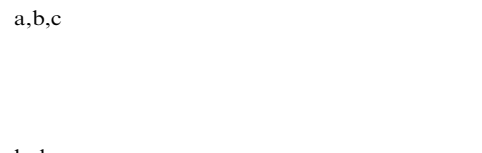 & $\begin{array}{l}{ }^{\mathrm{a}} \text { After } 6 \text { months, the wound was stable and } \\
\text { manageable } \\
\mathrm{b}, \mathrm{c} \text { Less time and costs compared to regular } \\
\text { care. Pressure ulcers surgery was avoided }\end{array}$ \\
\hline Phillips $^{12}$ & Pre-experiment & 11 & $\begin{array}{l}\mathrm{b}, \mathrm{d} \\
{ }^{\mathrm{e}} \mathrm{A} \text { description of problems } \\
\text { mentioned in the initial telephone } \\
\text { call after discharge }\end{array}$ & $\begin{array}{l}{ }^{\mathrm{b}} \text { An average of } 10 \text { video calls and six telephone } \\
\text { calls per client with an average length of } \\
23 \text { min. The intervention lasted to } 32 \text { weeks } \\
{ }^{\mathrm{d}} \text { Positive overall impressions } \\
{ }^{\mathrm{e}} \text { In all, } 10 \text { problems were mentioned by } 11 \\
\text { patients. Experience about the use of a } \\
\text { videophone and the appropriate number of } \\
\text { video-consultations to offer }\end{array}$ \\
\hline Phillips $^{13}$ & $\begin{array}{l}\text { Quasi-experiment } \\
\text { (matching) }\end{array}$ & $\begin{array}{l}\text { Video group } 12 \\
\text { Standard care } 10 \\
\text { Telephone group } 13\end{array}$ & ${ }^{\mathrm{e}, \mathrm{e}}$ Employment status & $\begin{array}{l}{ }^{\mathrm{a}} \text { The video group had the greatest number of } \\
\text { pressure ulcers. The telehealth intervention } \\
\text { improved ulcer tracking and management } \\
{ }^{\mathrm{b}} \text { Small differences between the video and } \\
\text { telephone groups } \\
{ }^{\mathrm{e}} \text { The video group had the lowest preinjury rate } \\
\text { of employment and the highest postinjury rate } \\
\text { of employment. No significant differences at } \\
P<0.05\end{array}$ \\
\hline Phillips $^{14}$ & Experiment & $\begin{array}{l}\text { Video group } 36 \\
\text { Telephone group } 36 \\
\text { Standard care } 39\end{array}$ & $\begin{array}{l}{ }^{\mathrm{b}} \text { Employment status, a self-report } \\
\text { measure of handicap, quality of }\end{array}$ & $\begin{array}{l}{ }^{b} \text { Mean annual hospital days were } 3.00 \text { for the } \\
\text { video group, } 5.22 \text { for the telephone group, and } \\
7.95 \text { for the standard care group }\end{array}$ \\
\hline & & & $\begin{array}{l}\text { life (by means of quality of well- } \\
\text { being, QWB) and depression (by } \\
\text { means of the Centre for } \\
\text { Epidemiologic Studies Depression } \\
\text { scale, CES-D) }\end{array}$ & $\begin{array}{l}{ }^{e} \text { QWB scores did not differ significantly at the } \\
\text { end of the intervention period. At year } 1 \\
\text { postdischarge, scores were significantly higher } \\
\text { for both the intervention groups compared to } \\
\text { standard care } \\
\text { Depressive symptoms declined for all three } \\
\text { groups, at one year postdischarge the video } \\
\text { group had the most of depressive symptoms }\end{array}$ \\
\hline Barber $^{16}$ & Pre-experiment & 17 & $\mathrm{a}$ & $\begin{array}{l}\text { an all, } 11 \text { patients responded sufficiently to } \\
\text { counselling }\end{array}$ \\
\hline Dover $^{17}$ & Quasi-experiment & $\begin{array}{l}\text { Intervention group } 135 \\
\text { Comparison group } 10\end{array}$ & 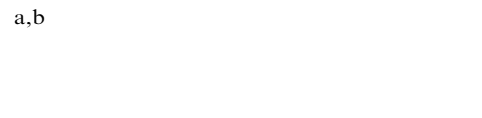 & $\begin{array}{l}\text { a,b The incidence of pressure sores and } \\
\text { readmissions were higher in the control group. } \\
\text { No testing for significance }\end{array}$ \\
\hline Dunn $^{18}$ & Quasi-experiment & $\begin{array}{l}\text { Intervention group } 235 \\
\text { Comparison group } 136\end{array}$ & $\begin{array}{l}{ }^{\mathrm{a} B y} \text { means of the Secondary } \\
\text { Conditions Screening Instrument } \\
\text { eSelf-reported health, } \\
\text { independence, and depression (by } \\
\text { means of the Check Your Health } \\
\text { Questionnaire) }\end{array}$ & $\begin{array}{l}{ }^{\mathrm{a}} \text { There were similar secondary conditions in } \\
\text { the two groups, but higher frequency and } \\
\text { severity in the comparison group } \\
{ }^{\mathrm{e}} \text { Significant better subjective health, } \\
\text { independence, and less depression in the } \\
\text { experimental group compared to the } \\
\text { comparison group }\end{array}$ \\
\hline
\end{tabular}


Table 2 Continued

\begin{tabular}{|c|c|c|c|c|}
\hline Author & Design & $\mathrm{N}$ & Outcome measures* & Outcomes $^{\mathrm{a}}$ \\
\hline Lapierre $^{20}$ & Pre-experiment & $?$ & $\begin{array}{l}{ }^{\mathrm{d}} \text { By means of the Out-Patient } \\
\text { Satisfaction Questionnaire }\end{array}$ & $\begin{array}{l}{ }^{\mathrm{d}} \text { In all, } 93 \% \text { of the respondents were either } \\
\text { satisfied or very satisfied }\end{array}$ \\
\hline Beer $^{22}$ & Pre-experiment & $?$ & b & $\begin{array}{l}{ }^{\mathrm{b}} \text { There was a } 34 \% \text { decrease in the incidence of } \\
\text { hospitalisations for pressure sore treatment } \\
\text { from the years } 1971-1973 \text { to the period 1977- } \\
1979 \text { and bed occupancy per year for their } \\
\text { treatment decreased by } 30 \text { per cent. There were } \\
\text { only a small number of hospitalisations for the } \\
\text { treatment of urinary tract infections }\end{array}$ \\
\hline Fine $^{23}$ & Pre-experiment & 519 in 5 years & 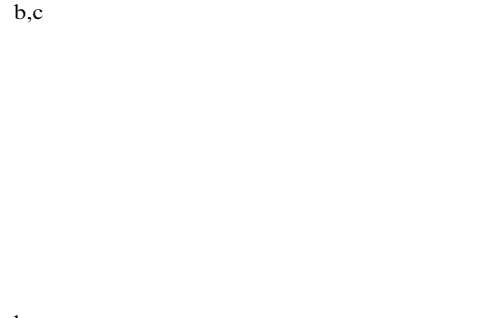 & $\begin{array}{l}\mathrm{b}, \mathrm{c} \text { Descriptive information regarding the type, } \\
\text { amount and costs of care, and the number of } \\
\text { patients who completed the programme or not. } \\
\text { The authors had the impression that the care is } \\
\text { a valid concept, although the most appropriate } \\
\text { role for the team still remained to be clarified. } \\
\text { It was their belief that direct care first should } \\
\text { be provided before assuming responsibility for } \\
\text { educating other health professionals }\end{array}$ \\
\hline Jones $^{24}$ & Pre-experiment & $?$ & $\begin{array}{l}\mathrm{b} \\
{ }^{\mathrm{e}} \text { The number of cases in which the } \\
\text { programme facilitated difficult } \\
\text { discharges (persons with high- }\end{array}$ & $\begin{array}{l}{ }^{\mathrm{b}} \text { Since the home visiting began, there were } \\
\text { fewer readmissions for sores, and the average } \\
\text { length of stay for sore treatment declined from } \\
6 \text { to } 3.5 \text { months }\end{array}$ \\
\hline
\end{tabular}

$\mathrm{Beck}^{26}$

Pre-experiment

Dinsdale $^{28}$

Experiment

Pollack $^{31}$

Pre-experiment
A total of 25 workshop and home visit

participants of whom

nine were consumers

Community-based

programme, 12

Hospital-based

programme, 11 programme facilitated difficult

discharges (persons with highlevel tetraplegia), and allowed the discovering of equipment and house adaptation needs

'Participant's knowledge perception

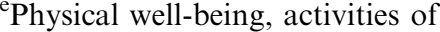
daily living, psychological

functioning, social vocational functioning and needs detected at follow-up

${ }^{\mathrm{e}}$ The effectiveness of the programme (not elaborated)
${ }^{\mathrm{e}}$ The programme facilitated discharge in 22 difficult cases and often allowed discovery of the need for various equipments

${ }^{\mathrm{b}}$ Two consumers asked for support, two were hospitalised for elective bladder surgery

${ }^{d}$ High satisfaction $(87-100 \%)$ with the programme

${ }^{\mathrm{e}}$ Increased knowledge perception on six out of

17 items immediately after the workshop

${ }^{b}$ Seven readmissions in the intervention group

against 13 in the control group

${ }^{\mathrm{e}}$ Both groups were equally functioning with

respect to ADL

More patients in the intervention group

received emotional support

Both groups had about the same rate of integration

More housing, vocational, and health agency support in the intervention group

The two programmes were roughly equivalent in identifying potential problems

${ }^{\mathrm{e}} 100 \%$ of the participants found the programme to be helpful and $85.7 \%$ expressed that the programme is meeting expectations 
The level of functioning after discharge, compared to the leve of functioning at discharge, reasons for discharge from home care

The team members' agreement with the follow-up coordinator's role expectations. Address status, employment status, suggestions that might have made transition from rehabilitation centre to home easier, and suggestions for other patients
${ }^{\mathrm{b}}$ There were 179 hospitalisations. In all, 11 patients were admitted due to pressure sores. A total of 18 patients who were on home care for more than one year spent from 0.8 to $27.4 \%$ of their home care days in the hospital. Patients were hospitalised more promptly but for briefer periods

${ }^{\mathrm{e}}$ Most patients retained the level of functioning of the moment of discharge. Of the 31 patients, 21 were discharged and 10 were still on the programme. Complications were recognised

before they became major. Home care helped

to keep families intact

$61 \%$ of the patients were hospitalised at least once after discharge

${ }^{\mathrm{e}}$ The team members agreed with the role expectations

Of the patients, $91 \%$ had no problems for which they thought they had not been

prepared. A total of $21 \%$ of the patients made suggestions to make the transition to home easier. In all, $63 \%$ had suggestions for other patients. Of the patients, $42 \%$ stated to have had suggestions that may have prevented

problems

Patients perceived relatively few problems and felt prepared for returning to the home and the community. The authors felt that the follow-up programme was the major reason for these findings

*In the 'outcome measures' column:

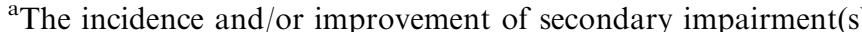

${ }^{\mathrm{b}}$ Health care utilisation

${ }^{\mathrm{c}}$ Costs of the care

'Patients' satisfaction with the care

'Outcome measurement as described in the table

**In the 'outcomes' column the 'superscript letters' also refer to the above mentioned outcome measures, per outcome measure the results are given 
publications initially selected by at least two of the three researchers, including publications without abstracts. We are therefore reasonably confident that we did not miss relevant publications that should have been included in this review.

Second, the review may possibly be subject to 'publication bias', implying that several existing follow-up care programmes and their evaluations might not have been described in the literature. Since we have got to know several follow-up programmes in practice that were not included in our study, we assume the presence of publication bias.

Thirdly, 18 out of the 24 publications included in this study were from the USA, two were from Canada, ${ }^{20,28}$ two from the UK, ${ }^{17,24}$ and two from Australia. ${ }^{22,27}$ Therefore, the results cannot be translated to other countries. The obvious difference between the number of follow-up care programmes performed in the USA compared to those in other parts of the world, such as North-West Europe, may be explained by the fact that the content of follow-up care programmes in Europe might have not been communicated in English or German. Another reason for the high percentage of US follow-up care programmes may be the difference regarding the duration of in-patient rehabilitation. Since the duration of in-patient rehabilitation in the USA is relatively short, the need for follow-up care in the USA may be higher.

All this contributes to the most important conclusion of this review: there is a need for the development, the publication and the well-designed evaluation of followup care programmes for persons with SCI. We encourage rehabilitation centres, specialised in the rehabilitation of persons with SCI, to take the initiative to organise follow-up care, preferably in cooperation with primary care professionals and/or patient organisations. Since primary care professionals rarely have sufficient knowledge and experience about the specific care persons with SCI need (due to the low prevalence of persons with SCI), it is important that the expertise of specialised rehabilitation centres is in some way or another available for persons with SCI living in the community and that these centres should take the initiative in organising follow-up care. Cooperation with primary care professionals is preferable, since they are the persons first and foremost to deliver care at home. From our review we learned that follow-up care programmes vary widely with regard to aim and methods. To facilitate comparisons of design and results of such programmes, we propose a rough classification system, based on three dimensions:

1. Classification according to the aim of follow-up care:

- specific aim like preventing or treating one or more secondary complications;

- generic aim like the promotion of quality of life, participation and community reintegration;

- combination of the aims mentioned above.
2. Classification according to the method of follow-up care:

- preventive activities directly aimed at individual patients or patient groups;

- therapeutic activities directly aimed at individual patients or patient groups;

- activities aimed at the promotion of continuity of care;

- combination of the methods mentioned above.

3. Classification according to the localisation of the care:

- at the patient's home;

- in the rehabilitation centre;

- both at the patient's home and in the rehabilitation centre making use of communication technologies;

- combination of methods mentioned above.

With regard to the evaluation of follow-up care programmes we think it is important to evaluate the follow-up care with regard to its effectiveness (effects on the prevalence on secondary impairments). Furthermore, attention should also be paid to the effects regarding the efficiency (costs and health-care utilisation) and the effects on quality of care (satisfaction and continuity).

\section{Acknowledgements}

The study was supported by the Netherlands Organisation for Health Research and Development, ZonMw, Rehabilitation programme, Grant no. 01432030 .

\section{References}

1 Anson CA, Shepherd C. Incidence of secondary complications in spinal cord injury. Int J Rehab Res 1996; 19: 55-66.

2 Bloemen-Vrencken JH, de Witte LP. Post-discharge nursing problems of spinal cord injured patients: on which fields can nurses contribute to rehabilitation? Clin Rehab 2003; 17: 890-898.

3 Bloemen-Vrencken JHA, Post MWM, Hendriks J, De Reus ECE, de Witte LP. Health problems found in persons with spinal cord injury living in the Netherlands, 2004, accepted for publication in Disability and Rehabilitation.

4 Cox RJ, Amsters DI, Pershouse KJ. The need for a multidisciplinary outreach service for people with spinal cord injury living in the community. Clin Rehab 2001; 15: 600-606.

5 Ernst JL, Thomas LM, Hahnstadt WA, Piskule AA. The self-identified long-term care needs of persons with SCI. SCI Psychosocial Process 1998; 1: 127-132.

6 Glidden MM. Spinal cord injury and case management. Top Spinal Cord Inj Rehab 1999; 4: 16-23.

7 Mattson J. Case management: a historical and future perspective of its influence on outcome for persons who have sustained spinal cord injury. Top Spinal Cord Inj Rehab 1999; 4: 30-37.

8 Rawl SM, Easton KL, Kwiatkowski S, Zemen D, Burczyk B. Effectiveness of a nurse-managed follow-up program for rehabilitation patients after discharge. Rehab Nurs 1998; 23: 204-209. 
9 Polit DF, Hungler BP. Nursing Research: Principles and Methods, 4th edn, Lippincott Company: Philadelphia, 1991.

10 Mathewson C, Adkins VK, Lenyoun MA, Schmidt AM, Jones ML. Using telemedicine in the treatment of pressure ulcers. Ostomy Wound Manage 1999; 45: 58-62.

11 Mathewson C, Adkins VK, Jones ML. Initial experiences with telerehabilitation and contingency management programs for the prevention and management of pressure ulceration in patients with spinal cord injuries. $J$ Wound Ostomy Continence Nurs 2000; 27: 269-271.

12 Phillips VL, Temkin AJ, Vesmarovich SH, Burns R. A feasibility study of video-based home telecare for clients with spinal cord injuries. J Telemed Telecare 1998; 4: 219-223.

13 Phillips VL, Temkin A, Vesmarovich S, Burns R, Idleman L. Using telehealth interventions to prevent pressure ulcers in newly injured spinal cord injury patients post-discharge. Results from a pilot study. Int J Technol Assess Health Care 1999; 15: 749-755.

14 Phillips VL, Vesmarovich S, Hauber R, Wiggers E, Egner A. Telehealth: reaching out to newly injured spinal cord patients. Public Health Rep 2001; 116(Suppl 1): 94-102.

15 Weinel D. The sunshine network teleconsultation initiative for SCI veterans in community settings. SCI Nurs 2000; 17: 22-23.

16 Barber DB, Woodard FL, Rogers SJ, Able AC. The efficacy of nursing education as an intervention in the treatment of recurrent urinary tract infections in individuals with spinal cord injury. SCI Nurs 1999; 16: 54-56.

17 Dover H, Pickard W, Swain I, Grundy D. The effectiveness of a pressure clinic in preventing pressure sores. Paraplegia 1992; 30: 267-272.

18 Dunn M, Love L, Ravesloot C. Subjective health in spinal cord injury after outpatient healthcare follow-up. Spinal Cord 2000; 38: 84-91.

19 Ferguson I. Growing a SCI support clinic - in the VA health care system. SCI Psychosocial-Process (SCI-PSYCHOSOC-PROCESS) 2000; 13: 129-132.
20 Lapierre NM. Innovative approach in rehabilitation nursing: providing primary care to tertiary care patients. Can J Nurs Leadersh 1999; 12: 23-24.

21 Remington H. How successful has a nurse-managed outpatient SCI clinic been in your hospital? SCI Nurs 1991; 8: 30.

22 Beer NI. The role of the home visiting nurse in the total education programme of spinal cord injured persons. Paraplegia 1984; 22: 311-315.

23 Fine PR, Better SR, Engstrand JL. The operation of a hospital based specialty home health team: activities and associated costs. Arn J 1978; 3: 5-11.

24 Jones HW. A follow-up service-supplemented by domicillary visits. Paraplegia 1972; 10: 111-114.

25 Cioschi HM, Goodman CL. A lifetime case management model for persons with spinal cord injury. J Case Manag 1994; 3: 117-123.

26 Beck LA, Scroggins LM. Optimizing health of individuals with tetraplegia. SCI Nurs 2001; 18: 181-186.

27 Brown DJ, Judd FK, Ungar GH. Continuing care of the spinal cord injured. Paraplegia 1987; 25: 296-300.

28 Dinsdale S, Thurber D, Hough E, Rencz S. Community based monitoring for spinal man. Can J Public Health 1981; 72: 195-198.

29 Duci B, Saperstein I. SCI home care: transitional rehabilitation as a component of follow-up care. SCI Nurs 1986; 3: 6-9.

30 Lathbury K. The road ahead - managing a spinal cord injury. Case Manager 2000; 11: 55-57.

31 Pollack SF, Zuger RR, Walsh J. Moving out services for education and support (MOSES): a model program for individuals with spinal cord injury. SCI Nurs 1992; 9: 79-82.

32 Steinberg FU. The management of patients with spinal cord injury by a hospital-based home care programme. Paraplegia 1975; 12: 246-250.

33 Warner BH, Taylor SK. Follow-up care evaluation: patient perspective. Rehab Nurs 1982; 7: 13-16, 24. 